\title{
Pitfalls and Progress in the Assessment of Function and Functioning in Ankylosing Sponylitis
}

\author{
Murat BİRTANE \\ Department of Physical Medicine and Rehabilitation, Medical Faculty of Trakya University, Edirne, Turkey
}

Ankylosing spondylitis (AS) is a chronic inflammatory disease which may cause progressive changes in the axial skeleton and sacroiliac joints. It presents with inflammatory back pain, spinal stiffness, and finally permanent motion limitations in the spinal column. As a result, a gradual reduction in physical function can often be observed over time. The Ankylosing Spondylitis Assessment Study Group (ASAS) has developed a core set of parameters for clinical record-keeping for patients with AS that includes physical function, patient global assessment, spinal pain, spinal stiffness, spinal mobility, peripheral joints, enthesis, acute-phase reactants, and fatigue. ${ }^{[1]}$ Functional assessment is an integral part of global patient evaluations, whereas physical function cannot be adequately quantified with only a single parameter. There are a few specific instruments that are available which are a combination of function or daily living activity-related parameters that can be used to assess overall disability. To the best of my knowledge, the most commonly used instrument is the Bath Ankylosing Spondylitis Functional Index (BASFI), which has performed well with regard to reliability, validity, and sensitivity to change. ${ }^{[2]}$

Although the BASFI has been used in many clinical studies as a main outcome measure over the last two decades, it has been criticized with respect to its interpretation and potential to reflect all aspects of functioning.

According to the ASAS definition of partial remission, a value of less than 20/100 in each of the four response criteria (patient global assessment, spinal pain, function measured by the BASFI, and inflammation) should be reached by an AS patient to satisfy the condition. ${ }^{[3]}$ However, there is always a significant possibility that physical function can be impaired because of structural damage associated with AS along with disease activity, especially in the later phases of the disease. Hence, it would be impossible for a patient to be in partial remission even if he had been treated very successfully with regard to disease activity if he had residual structural limitation in the spine and a BASFI score of higher than 2. With similar reasoning, an international task force recently published recommendations that did not strongly recommend that functional assessment be performed nor suggest that it be compulsorily documented in routine clinical practice to guide treatment decisions concerning spondyloarthritis, including AS. ${ }^{[4]}$ There is clearly an unmet need to separate the effects of inflammation and structural damage with regard to function. If we know the basal effect of the structural limitations in a patient, then we can produce rational targets for functional improvement by suppressing disease activity.

The BASFI is a self-reported instrument that measures the patient's perceived level of function during daily activities through the use of standardized questions. It is short, easy to apply, and inexpensive and has proven to be beneficial for evaluating various aspects of physical function. Moreover, there is no influence by an observer, and only the patient's point of view is reflected. However, like the other self reported measures, the BASFI evaluates the experiences of the patients rather than their real potential to perform daily life activities, making it open to discrepancies stemming from personality attitudes, depression, poor cognitive function,

\footnotetext{
Correspondence: Murat Birtane, M.D. Trakya Üniversitesi Tıp Fakültesi, Fizik Tedavi ve Rehabilitasyon Anabilim Dalı, 22030 Edirne, Turkey.

Tel: +90 532 - 7759968 e-mail: mbirtane@hotmail.com

C2013 Turkish League Against Rheumatism. All rights reserved.
} 
language, educational level, expectations, and pain. Recently, van Weely et al. ${ }^{[5]}$ developed a performancebased test that focused on physical function for AS patients that was based on the items described in the BASFI with the hope of overcoming the limitations of the self-reported measures. They claim that performance measures are influenced less by discrepancies between the perceptions of a person's ability and true performance than by self-reported measures. However, measuring the duration of time it takes to complete an activity requires patient motivation, which is not always possible and may not provide much information about the patient's attitudes in a real life setting. Discussions regarding this issue will doubtless continue, and in the near future, hopefully there will be an excellent functional evaluation tool available for use with AS patients.

Functional evaluation in patients with AS is, in fact, quite complicated. Many variables other than the pain associated with inflammation and structural limitations can affect the final functional status. In a recent study, the total explained variance of the BASFI increased from $32 \%$ to $56 \%$ in cases in which psychological variables such as depression, passive coping, arthritis, and helplessness were added to the clinical and demographic variables. ${ }^{[6]}$ This finding brings to mind that the available instruments which quantify functional status in AS project only a small fragment of the full spectrum of global functioning.

The term "functioning" has increasingly gained popularity when examining patients with chronic diseases. "Functioning" is often referred to as "function"; however, the term "function" reflects only physical function and does not cover the complexity of global functioning. ${ }^{[7]}$ In addition, the International Classification of Functioning, Disability, and Health, more commonly known as ICF, a more systematic and universal model to assess functioning and disability in AS as well as in other chronic diseases and conditions, has been developed, and it has received the approval by the World Health Organization (WHO). This model takes into account biopsychosocial interaction and adds the impact of environmental or personal contextual factors into its interpretation of "functioning". The ICF also provides a detailed definition of "functioning" and "disability" in a way that all health professionals can understand. ${ }^{[7]}$ This instrument consists of 1,545 categories allocated into four components: (i) body functions (psychological and physiological functions), (ii) structures (anatomical parts), (iii) activities (execution of tasks) and participation (involvement in a life situation), and (iv) environmental and personal factors. ${ }^{[8]}$

Different relevant variables constitute the core sets used in clinical practice for a given disease. During the elucidation of the relevant parameters for AS, 80 categories were included in the comprehensive core set, with 23 (29\%) categories for body functions, 19 (24\%) for body structures, 24 (30\%) for activities and participation, and 14 (17\%) for environmental factors. Additionally, 19 categories, consisting of six (32\%) for body functions, four (21\%) for body structures, seven (37\%) for activities and participation, and two (10\%) for environmental factors, were selected for a smaller core set. ${ }^{[9]}$ This set contained the following variables: (i) body functions: b280 sensation of pain, b710 mobility of joint functions, b780 sensations related to muscles and movement functions, b130 energy and drive functions, b134 sleep functions, b152 emotional functions, and b455 exercise tolerance functions; (ii) body structures: s760 structure of the trunk, s740 structures of the pelvic region, s770 additional musculoskeletal structures related to movement, s750 structure of the lower extremity; (iii) activities and participation: $\mathrm{d} 230$ carrying out daily routines, $\mathrm{d} 410$ changing basic body positions, d450 walking, d845 acquiring, keeping, and terminating a job, d850 remunerative employment, $\mathrm{d} 760$ family relationships, d920 recreation and leisure, and $\mathrm{d} 475$ driving; and (iv) environmental factors: e110 products or substances for personal consumption and e3 support and relationships. ${ }^{[9]}$ The ICF assessment uses a fivepoint scale for quantifying each variable in which 4 indicates a level of complete impairment, 3 signifies severe impairment, 2 shows moderate impairment, 1 denotes mild impairment, and 0 indicates no impairment. ${ }^{[10]}$

In our clinic, we evaluated all of the ICF brief core set parameters using 100 AS patients and mapped the different aspects of functioning which we believe are crucial from the perspective of a rehabilitative approach. We have not yet published the data, but roughly speaking, we found severe and very severe impairment ranging from $5-60 \%$ in various items. I feel there is still long way to go to perfect physical function and functioning in AS patients. The ICF core sets will provide a deeper insight, especially for rehabilitation specialists, during the follow-up of AS patients, but there is still a need to develop a health index for AS based on the ICF and its core sets for use in clinical settings. 


\section{Declaration of conflicting interests}

The author declared no conflicts of interest with respect to the authorship and/or publication of this article.

\section{Funding}

The author received no financial support for the research and/or authorship of this article.

\section{REFERENCES}

1. van der Heijde D, Bellamy $\mathrm{N}$, Calin A, Dougados $\mathrm{M}$, Khan MA, van der Linden S. Preliminary core sets for endpoints in ankylosing spondylitis. Assessments in Ankylosing Spondylitis Working Group. J Rheumatol 1997;24:2225-9.

2. Zochling J, Braun J. Assessment of ankylosing spondylitis. Clin Exp Rheumatol 2005;23(5 Suppl 39):S133-41.

3. Anderson JJ, Baron G, van der Heijde D, Felson DT, Dougados M. Ankylosing spondylitis assessment group preliminary definition of short-term improvement in ankylosing spondylitis. Arthritis Rheum 2001;44:1876-86.

4. Smolen JS, Braun J, Dougados M, Emery P, Fitzgerald O, Helliwell $\mathrm{P}$, et al. Treating spondyloarthritis, including ankylosing spondylitis and psoriatic arthritis, to target: recommendations of an international task force. Ann Rheum Dis 2013. [Epub ahead of print]
5. van Weely SF, van Denderen CJ, van der Horst-Bruinsma IE, Nurmohamed MT, Dijkmans BA, Dekker J, et al. Reproducibility of performance measures of physical function based on the BASFI, in ankylosing spondylitis. Rheumatology (Oxford) 2009;48:1254-60.

6. Brionez TF, Assassi S, Reveille JD, Learch TJ, Diekman L, Ward MM, et al. Psychological correlates of selfreported functional limitation in patients with ankylosing spondylitis. Arthritis Res Ther 2009;11:R182.

7. Kiltz U, van der Heijde D, Cieza A, Boonen A, Stucki G, Ustün B, et al. Developing and validating an index for measuring health in patients with ankylosing spondylitis. Rheumatology (Oxford) 2011;50:894-8.

8. Boonen A, van Berkel M, Kirchberger I, Cieza A, Stucki G, van der Heijde D. Aspects relevant for functioning in patients with ankylosing spondylitis according to the health professionals: a Delphi study with the ICF as reference. Rheumatology (Oxford) 2009;48:997-1002.

9. Boonen A, Braun J, van der Horst Bruinsma IE, Huang F, Maksymowych W, Kostanjsek N, et al. ASAS/WHO ICF Core Sets for ankylosing spondylitis (AS): how to classify the impact of AS on functioning and health. Ann Rheum Dis 2010;69:102-7.

10. Saketkoo LA, Escorpizo R, Keen KJ, Fligelstone K, Distler O. International Classification of Functioning, Disability and Health Core Set construction in systemic sclerosis and other rheumatic diseases: a EUSTAR initiative. Rheumatology (Oxford) 2012;51:2170-6. 